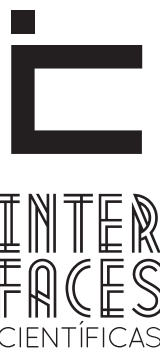

EDUCAÇÃO

\title{
O ESCOTISMO COMO ASSOCIAÇ̃̃O VOLUNTÁRIIA NO INÍCIO DO SÉCULO XX: PRÁTICA PEDAGÓGICA EXTRA-ESCOLAR
}

\author{
Ricardo Rocha Rabelo ${ }^{1}$
}

\section{RESUMO}

O Escotismo, prática educativa gestada como associação voluntária, surge no início do século XX paripassu com o processo de renovação pedagógica que se sedimentava na Europa e nos Estados Unidos. Fundamentava-se em princípios baseados na educação pelos sentidos. 0 presente artigo tem por objeto de estudo as obras acerca do Escotismo em especial aquelas que tratam de sua gênese e do escotismo como método pedagógico de educação extra-escolar. O objetivo é evidenciar o surgimento e o desenvolvimento desta prática pedagógica e analisá-la à luz do movimento
Raylane Andreza Dias Navarro Barreto

das associações voluntárias, disseminadas na Europa e nos Estados Unidos, no final do século XIX. A pesquisa é do tipo bibliográfico e o seu trato é qualitativo. As fontes utilizadas são bibliográficas e apóiam, sobretudo, em textos do fundador do Escotismo, pesquisadores da temática e de militantes do Movimento escoteiro.

\section{PALAVRAS-CHAVE:}

Associação Voluntária. Escotismo. Prática Educativa. 


\section{ABSTRACT}

Scouting, educational practice gestated as voluntary association, comes at the beginning of the twentieth century simultaneously with pedagogical renewal process with took hold in Europe and the United States. It was based on principles-based education through the senses. This article intends to study the works about Scouting in particular those dealing with the genesis and scouting as a pedagogical method for extra-school education. The aim is to highlight the emergence and development of pedagogical practice and analyze it in light of the movement of voluntary associations, widespread in Europe and the United States in the late nineteenth century. The research is bibliographical and their treatment is qualitative. The sources used include bibliographic and support, especially in texts of the founder of Scouting, researchers of subject area and militants of the Scout Movement.

\section{KEYWORDS}

Voluntary Association. Scouting. Educational Practice.

\section{RESUMEN}

El movimiento Scout, práctica educativa concebida como asociación voluntaria, surgió en el comienzo del siglo XX paripassu con el proceso de renovación pedagógica que sedimentava en Europa y los Estados Unidos. Se fundamenta en principios basados en la educación a través de los sentidos. Este artículo tiene la intención de estudiar las obras sobre el Movimiento Scout, en particular las relacionados con su génesis y del scoutismo como método pedagógico de educación extraescolar. El objetivo es poner de relieve el surgimiento y desarrollo de esta práctica pedagógica y analizarla a la luz del movimiento de las asociaciones voluntarias, diseminadasdas en Europa y los Estados Unidos a fines del siglo XIX. La investigación es del tipo bibliográficos y su tratamiento es de carácter cualitativo. Las fuentes utilizadas son bibliográficas y se apoyan, especialmente, en los textos del fundador del Movimiento Scout, investigadores y activistas del tema del Movimiento Scout.

\section{PALABRAS CLAVE}

Asociación Voluntaria. El Movimiento Scout. La Práctica Educativa.

\section{INTRODUÇ̃̃O}

O Escotismo surge no início do século XX paripassu com o processo de renovação pedagógica que se sedimentava na Europa e nos Estados Unidos. Foi gestado como um tipo de associação voluntária e embora tenha surgido como uma prática educacional extra-escolar fundamentava-se em princípios baseados na educação pelos sentidos, pela observação e pela experiência, características estas do método intuitivo, propalado por Pestalozzi (1946, p. 15), segundo ele "Aprende-se a fazer e a conhecer, fazendo"
0 presente artigo tem por objeto de estudo as obras acerca do Escotismo em especial aquelas que tratam de sua gênese e do escotismo como método pedagógico de educação extra-escolar. Por educação extra-escolar entendam-se as atividades e experiências diversas ocorridas fora da escola e que complementam a aprendizagem escolar (FÁVERO, 2007).

O objetivo é evidenciar o surgimento e o desenvolvimento desta prática pedagógica e analisá-la à luz do movimento das associações voluntárias, disseminadas na Europa e nos Estados Unidos, no final do 
século XIX. A pesquisa é do tipo bibliográfico e o seu trato é qualitativo. As fontes utilizadas são bibliográficas e apóiam, sobretudo, em textos do fundador do Escotismo, pesquisadores da temática e de militantes do Movimento escoteiro.

\section{ESCOTISMO NO CENÁRIO PEDAGÓGICO DO SÉCULO XX}

O Movimento Escoteiro, reconhecidamente um fenômeno social, foi marcado pelo pragmatismo norte-americano e pelas pedagogias ativas do final do século XIX, dentre as quais se pode citar a idealizada por Maria Montessori, cuja base do seu método balizava-se pelo caráter experimental da natureza da criança, enfatizando as atividades sensório-motoras, desenvolvidas por intermédio de exercícios da vida prática. De modo que o Escotismo surgiu em uma época onde o clamor por um novo modelo de Educação era latente, por parte de trabalhadores e grupos sociais elitistas dos Estados Unidos, da Europa e várias outras regiões do planeta.

Apenas duas décadas após seu surgimento, o Escotismo estava presente em praticamente todos os cantos do mundo, tendo como adeptos e representantes, membros dos mais diferentes tipos de povos, etnias e credos. Sua pedagogia abarca jovens dos sete aos vinte e um anos de idade, incentivados a buscar preceitos emancipatórios e do autogoverno, trabalhados de formas específicas, as quais os jovens desconheciam, levando-se em conta as diferentes faixas etárias que o configuram.

O Escotismo é um movimento de educação não-formal, criado na Inglaterra no ano de 1907, pelo lord Banden-Powell ${ }^{1}$, que assim o definiu:

1 Reprovado nos exames de ingresso das universidades de Oxford e Christ Church, Baden-Powell faz exame para oficial do exército inglês, sendo aprovado, aos dezenove anos de idade. Daquele
Escotismo é um jogo para jovens, dirigido por eles mesmos, no qual irmãos mais velhos proporcionam aos mais moços um ambiente sadio e os encorajam à prática das atividades também sadias que auxiliem o desenvolvimento do espírito de cidadania. [...] Sua maior atração reside no contato e estudo da natureza, a vida ao ar livre, os trabalhos manuais em madeira, rústicos e toscos. Ele atua diretamente sobre o individuo e não sobre o conjunto. [...] Ele cultiva e eleva tanto o intelecto, como as qualidades puramente físicas e morais. (POWELL, 2000, p. 26)

Nasceu a partir de um acampamento realizado na ilha de Brownsea ${ }^{2}$ na Inglaterra, onde participaram vinte rapazes entre pobres e ricos, onde, o escotismo foi oficialmente disseminado com o objetivo de colocar em prática os ensinamentos que seu criador havia planejado. Baden-Powell queria mostrar aos jovens ingleses que,

Em vez de vagabundear sem objetivo e das conversas pornográficas da esquina você encontrará muito o que fazer sob a forma de excursões, acampamentos e outros divertimentos varonis ao ar livre e uma espécie de clube limpo para freqüentar durante a semana - a sede dos Pioneiros. (POWELL, 1984, p. 127)

momento em diante, trilharia uma carreira de sucesso, com inúmeras condecorações e títulos honoríficos, até galgar o posto de General, aos 43 anos de idade, tornando-se o mais jovem General da história da Inglaterra, o que o faria ser reconhecido como Lord Baden-Powell. (BOULANGER, 2000).

2 Localizada na parte sul da Inglaterra, a ilha de Brownsea possui aproximadamente três quilômetros de extensão e dois de largura. Conta com muitos bosques, alguns deles com clareiras de arbustos. A itha era grande, com muitos bosques, alguns deles com clareiras de arbustos. (BOULANGER, 2000). 
Na essência do Escotismo, conforme as palavras de seu fundador "[...] devem ser subtendidas a característica da vida e o trabalho dos grandes exploradores e colonizadores, dos bandeirantes e sertanistas, dos descobridores e velhos lobos do mar e dos pioneiros da aeronáutica (POWELL, 2000, p. 31).

0 intuito era levar o jovem a transformar-se em um cidadão, com qualidades morais e éticas, além de ser responsável por suas atitudes, o que inclui o cumprimento de deveres para com o grupo escoteiro e a sociedade em geral. Idealizado como um método, o Escotismo tem como principais características: a observação para sobrevivência, o primar pela saúde corporal, o patriotismo, noções de cavalheirismo e técnicas de salvamento (na terra e no mar), o que o legitima como um movimento de educação para a cidadania. Pode ser definido como:

[...] Pedagogia organizada durante a primeira década do século XX, falando em ensinar disciplina aos jovens, fixar valores, desenvolver habilidades e difundir saberes, conforme alguns padrões recorrentes às práticas da Pedagogia Moderna naquele período [...]. (NASCIMENTO, 2005, p. 252)

Desenvolveu-se num período em que o interesse internacional por uma pedagogia que levava em consideração, por exemplo, o método de projetos de William KillPatrick, que assemelhava-se ao método escoteiro pela intencionalidade, aprendizagem pela ação e autogoverno (CAMBI, 1999).

O Escotismo apresenta-se como projeto complementar a escola, muito embora, posteriormente, o Movimento Escoteiro acabe influenciando as instituições escolares, chegando a operacionalizar, com estas, a educação formal. Para isso, o idealizador do Escotismo entendia que a instrução escoteira "[...] poderia ser dada fora das horas de aula, pois não convém que os estudos escolares fiquem prejudicados durante o tempo de folga, durante o qual, tão comumente, ocupações inconvenientes vêm comprometer o trabalho realizado na escola." (BADEN-POWELL apud GABRIEL, 2003, p. 14)
Os princípios do Movimento Escoteiro materializam-se por meio de atividades práticas que se caracterizam pelo aprender fazendo, comumente realizados ao ar livre, na vida mateira (no campo). A ideia era conduzir o jovem a descobrir o prazer da auto-educação e do autodesenvolvimento. A finalidade do Movimento Escoteiro, assim, era menos a de encorajar a aquisição de conhecimentos e mais a de estimular a capacidade e o desejo de adquiri-los. Esta aprendizagem não formal:

[...] permite viver experiências pessoais que interiorizam e consolidam o conhecimento, as atitudes e as habilidades. Desta maneira, e do ponto de vista cognitivo, se substitui a simples recepção de informação pela efetiva aquisição de conhecimento; no domínio da afetividade, se substitui a norma imposta pela norma descoberta e a disciplina exterior pela interior; e, no campo motriz, a passividade receptiva do destinatário cede lugar à criatividade efetiva do realizador. (THOMÉ, 2006, p. 167)

Tendo em sua essência o espírito voluntário, o Movimento Escoteiro procura trabalhar nos jovens princípios que os façam bons cidadãos. Tais princípios, de ordem moral, ética, intelectual e espiritual, são vivenciados junto à natureza, pelas atividades ao ar livre em forma de acampamentos, excursões, jogos, competições e teatro, com o intuito de serem praticados nos distintos espaços da vida social. Fundamentos dessa forma de educar são encontrados na obra de Jean Pestalozzi, o qual afirmava: “[...] a instituição da natureza é o único fundamento próprio e verdadeiro da instrução humana, porque é o único alicerce do conhecimento humano." (PESTALOZZI, 1946, p. 63)

Inicialmente as pretensões do movimento escoteiro visavam instruções que levassem à auto-educação dos jovens ingleses. Baden-Powell constatou que muitos jovens ingleses estavam entregues aos vícios do fumo, do álcool, da libertinagem. Porém, o que ele, Baden Powell, não sabia, ao propor um método para a realidade inglesa da época, era ter aberto uma espécie da caixa de pandora do Escotismo, ou seja, o sucesso do movimento foi tamanho que extrapolou as 
circunscrições geográficas de seu país, disseminando-se mundo afora. Nem o mais otimista dos pensamentos de Baden-Powell poderia imaginar tais desdobramentos. (BOULANGER, 2000)

As características que fundamentam o Escotismo, notadamente explícitas pelo aprender fazendo ou educação pela ação, podem ser traduzidas em uma crítica à escola livresca e passiva, vivida por Baden-Powell. Seu fundador criticava principalmente o sistema de avaliação, de provas e de exames da escola tradicional. Esta crítica foi disseminada em consonância com o pensamento de intelectuais como John Dewey, Freud e Watson. Vale registrar que o modelo escolar vigente nas principais sociedades do século XIX estava sendo questionado fortemente por pensadores, filósofos e educadores. Este questionamento tem suas raízes a partir do século XVI e ganha vulto três séculos depois. Os principais intelectuais que

\section{ESCOTISMO NO BRASIL}

A entrada do Escotismo no Brasil aconteceu por volta de 1910, quando um grupo de militares da Marinha brasileira voltava de uma missão na Inglaterra, época que coincidiu com a eclosão do referido movimento naquele país. A partir daquele momento o

Tenente Eduardo Henrique Weaver que havia se apresentado, em 13 de julho de 1907, na Comissão Naval do Brasil na Inglaterra, sediada em Newcastle, entusiasmou-se pelo movimento de B-P, julgando sua introdução no país útil para nossa pátria. (BLOWER, 1999, p. 23)

Weaver foi autor do primeiro artigo sobre Escotismo publicado no Brasil, na edição de 1909 da "Revista Ilustração Brazileira”. Neste artigo, ele deixa bem claro:

Começaremos por bem frisar que os scouts não são militares nem ao menos militarizados; é essencial que produziram suas críticas e propostas foram Erasmo de Roterdã, Jonh Locke, Luiz Verney, Rousseau, Montessori, Pestalozzi e Jonh Dewey. O pensamento destes intelectuais contribuiu para influenciar diversos modelos e sistemas educacionais em todo o mundo, pois o modelo educacional questionado por estes pensadores era baseado no estudo livresco, na memorização e na repetição dos conteúdos. Outra característica deste modelo é centralidade do professor, tido como detentor dos saberes e transmissor por excelência dos conhecimentos.

No Brasil, a crítica à escola tradicional, na transição do século XIX para o século XX, culminou no que ficou conhecido pelo Movimento da Escola nova e teve no Escotismo uma parceria pedagógica. Vale ressaltar que o movimento da escola nova no Brasil primou por "[...] métodos que buscavam na 'atividade' a sua validação." (VIDAL, 2000, p. 498)

cada moço se compenetre de sua independência, do que se espera de sua iniciativa própria, e da consciência de sua responsabilidade que são os elementos formadores do seu caráter. (BLOWER, 1999, p. 25)

Embora sendo militar, fica evidenciado pelo Tenente Eduardo Henrique a preocupação em não se fazer do Escotismo uma versão infantilizada do militarismo, preocupação latente em Baden-Powell, seu difusor. Assim, na cidade de São Paulo, no dia 14 de junho de 1910, considerado como o dia da introdução do Escotismo no Brasil, os que assinaram a ata de fundação da primeira sede escoteira avisaram aos jornais e comunicaram a instalação da entidade. Vale ressaltar que outro personagem que contribuiu para a divulgação do Escotismo no Brasil foi o médico Mario Cardim, que se encontrava na Europa em 1910, onde conheceu pessoalmente Baden-Powell, sendo seu aluno em um curso de Chefe Escoteiro. 
Uma vez instalado no Brasil, o Escotismo, com seus padrões rigorosos de disciplinamento e com objetivos claros no tocante a transformar o menino em um cidadão conhecedor de seus direitos e deveres, passaria a entusiasmar diversas entidades sociais brasileiras como Igrejas, clubes esportivos e estabelecimentos de ensino. Em São Paulo, por exemplo,

A Primeira República configurou-se como momento de importantes transformações na escola paulista, tais como, a expansão do ensino primário, a preocupação com a formação de professores, a atenção cuidadosa para com a construção de espaços apropriados para o ensino, o surgimento de um mercado editorial voltado para temas pedagógicos e o aprimoramento de métodos e práticas pedagógicas como, por exemplo, a introdução do escotismo. (GABRIEL, 2003, p. 14)

Coadunando-se com os projetos de reformas educacionais que ocorriam no Brasil no início do século XX, o Escotismo, entre 1910 e 1924, já estava presente na maior parte dos estados brasileiros.

\section{ESCOTISMO ENQUANTO ASSOCIAÇÃO VOLUN- TÁRIA}

Baden-Powell, ao fundar o movimento escoteiro, tinha como propósito deixar claro uma das características principais sobre a qual o escotismo foi concebido, que é a de associação voluntária, concebida como um grupo de pessoas organizadas em prol de um objetivo e que tem uma hierarquia própria. Tal característica, que viria a se manifestar de forma latente mundo afora, foi evidenciada no primeiro acampamento dirigido por ele, na llha de Browsea. Os vinte rapazes, entre pobres e ricos, convidados para a experiência do acampamento, tinham entre dez e dezessete anos. 0 convite foi realizado pelo próprio Baden-Powell aos pais dos referidos jovens, que aprovaram o pedido após receberem explicações e serem convencidos quanto aos objetivos propostos para a inédita experiência. A pretensão de Baden-Powell com este acampamento era

Oferecer aos jovens a oportunidade de um aprendizado dinâmico e participativo, fora dos moldes engessadores da educação britânica do início do século $X X$, para retirá-los da ociosidade das ruas de Londres sem, no entanto, pretender substituir o papel da educação formal, mas antes, completá-lo dando ênfase no aprendizado junto à natureza, longe dos prédios e muros da cidade. (PEREIRA, 2004, p. 10).
A idéia de associação voluntária que Baden-Powell trouxe para o movimento escoteiro é também conhecida por sociedade de ideias. Este tipo de associação ou sociedade foi um dos pilares da constituição da democracia norte americana, no que se refere à formação cultural de seu povo, no inicio dos anos oitocentos. Para Nascimento (2005), a cultura norte americana foi fruto de uma experiência singular de imigrantes europeus, os quais buscavam no Novo Mundo a liberdade religiosa, dentre outras coisas. Neste tipo de sociedade, o indivíduo é tido como um sujeito social individual autônomo, protagonista da democracia. Sobre modelos de associação voluntária

Vale decir, como formas modernas de sociabilidad que ofrecieron nuevos modelos asociativos, en medio de una sociedad globalmente organizada en torno a una estructura corporativa jerárquica (ordenes) y compuesta en esencia por actores sociales coletivos. (COCHIN, 1921 apud BASTIAN, 1990, p. 7)

Em 1904, ao pesquisar nos Estados Unidos da América, Max Weber teve a oportunidade de conferir in loco e detectar o modelo de uma sociedade nova. Para ele "[...] as seitas protestantes pareciam ter, ali, seu maior âmbito de manifestações e na sua esteira 
floresceram as associações seculares, cívicas e "voluntárias”' (WEBER, 2002, p. 13).

\section{À luz de sua experiência americana, Weber}

\begin{abstract}
Impressionou-se acima de tudo com a eficiência grandiosa de um tipo de homem, criado pelas associações livres nas quais o indivíduo tinha de provar sua igualdade com outros, no qual não as ordens da autoridade, mas a decisão autônoma, o bom senso e a atitude responsável constituem a preparação para a cidadania. (WEBER, 2002, p. 13)
\end{abstract}

A difusão destas novas formas de associação é decorrência do Liberalismo da segunda metade do século XIX, que possibilitou a ampliação da consciência liberal e estimulou o surgimento dos mais variados tipos de associação que por sua vez buscaram aparato na Modernidade. Este movimento de difusão ocorreu, principalmente, nos Estados Unidos, de forma desarticulada, mas configurando-se como um modelo associativo horizontal, isto é, não hierárquico. Tal forma de sociabilidade tem como pano de fundo uma sociedade igualitária, calcada pela autonomia do sujeito social individual e pelo estímulo à difusão de preceitos morais como não fumar, não beber, manter a fidelidade matrimonial, combater jogos de azar e as regras que sedimentavam as bases da pedagogia proposta por Baden-Powell. A partir da experiência na ilha de Brownsea, Baden-powell deixou bem claro que
Fundamentalmente, a atividade do Escotismo era trabalho voluntário. As atividades escoteiras não interrompiam as horas habituais de trabalho que cada um desenvolvia nos escritórios, oficinas, escolas. As práticas do Escotismo eram exercitadas nas horas livres e o ingresso e a permanência no movimento eram inteiramente voluntários. (NASCIMENTO, 2008, p. 204).

Assim, a liberdade do jovem escoteiro de integrar-se e se desfiliar do movimento quando assim desejasse é respeitada, bem como a decisão democrática, pelo poder do voto, sobre os assuntos pertinentes a sua patrulha ${ }^{3}$. Na patrulha, como no grupo escoteiro, o jovem aprende a conviver em equipe e vivenciar o caráter voluntário das suas ações (CAMBI, 1999).

Em meio a uma disseminação de diversos tipos de associações voluntárias na Europa e nos Estados Unidos, o Escotismo foi a última das experiências referentes à segunda metade do século XIX. Embora o Escotismo tenha tido em sua concepção o caráter de associação voluntária, países como Alemanha, Itália e o próprio Brasil se apropriaram do movimento escoteiro para, através do escotismo escolar, militarizar a infância. Esta prática foi veementemente condenada por Baden-Powell, que apesar de ter sido militar do mais alto escalão - um general - deixou bem claro que o Escotismo não era uma espécie de militarismo, como muitos entenderam (BOULANGER, 2000).

\section{CONSIDERACÕ̃ES FINAIS}

O Escotismo é uma prática educativa surgida no início do século XX em meio a um processo de renovação pedagógica que emergia na Europa e nos Estados Unidos, principalmente. Embora se caracterize como extra-escolar, o Escotismo fundamenta-se em princípios educacionais que procuravam conferir novos contornos à educação formal daquela época, especialmente por meio do método intuitivo propalado por Pestalozzi. No Brasil, o Escotismo foi implantado concomitantemente ao processo de gestação de um modelo pedagógico escolar que ficou conhecido por Escola Nova, caracterizada também pelo método intuitivo.

$3 \quad$ No grupo escoteiro o jovem aprende a conviver em equipe (sistema de patrulha). Cada patrulha tem como símbolo e nome um animal, uma estrela ou uma constelação. Cf. Nascimento (2006). 
Uma das características do Escotismo e sob a qual ele foi gestado é a de ser tipicamente uma associação voluntaria. Este tipo de associação, muito presente na Europa do século XIX, foi também a base do processo de constituição da democracia norte americana. Neste tipo de associação, também conhecida por sociedade de ideias, o indivíduo é tido como um sujeito social individual autônomo, protagonista da democracia. Es- tas características configuram o Movimento Escoteiro como um todo e seus integrantes, de modo particular. Estudos sobre as práticas do Escotismo analisados à luz das associações voluntárias ainda são escassos e novas investigações podem contribuir para analisar o Escotismo sobre um novo ângulo o que pode ser considerado pertinente à História da Educação.

\section{REFERÊNCIAS}

BASTIAN, Jean Pierre. Protestantes, liberales y francomasones. Sociedades de ideas y modernidad em América Latina, Siglo XIX. México: Fondo de Cultura Económica/CEHILA, 1993.

BLOWER, Bernard David Almirante. História do Escotismo brasileiro: Os primórdios do Escotismo no Brasil. Vol. I. Tomo I - 1910-1924. Rio de Janeiro: CCME, 1999.

BOULANGER, Antonio. 0 Chapelão: Histórias da vida de Baden-Powell. Rio de Janeiro: Letra Capita, 2000.

CAMBI, Franco. História da Pedagogia. São Paulo: Editora Unesp, 1999.

FÁVERO, Osmar. Educação não-formal: contextos, percursos e sujeitos. Educação e Sociedade. v.28 n.99 Campinas Mai/Ago. 2007.

GABRIEL, Yara Cristina. Prescrições cívico-morais e a formação do cidadão: um estudo sobre a introdução do escotismo nas escolas públicas de São Paulo (1917 - 1922). Dissertação de Mestrado em Educação. PUC-SP, 2003.

NASCIMENTO, Ester Fraga Vilas-Bôas Carvalho do. Educar, Curar, Salvar: uma ilha de civilização no Brasil tropical. São Paulo: PUCSP, 2005. (Tese - Doutorado em Educação).

NASCIMENTO, Jorge Carvalho do. A escola de Baden-Powell: cultura escoteira, associação voluntária e escotismo de estado no Brasil. Rio de Janeiro: Imago, 2008.

NASCIMENTO, Jorge Carvalho do (Org.). Ensino superior, educação escolar e práticas educativas extra-Escolares. - São Cristóvão: UFS, 2006.

NASCIMENTO, Jorge Carvalho do (Org.) A Pedagogia do escotismo: o lord Baden-Powell e as reformas educacionais da primeira metade do século XX. In: Problemas de educação escolar e extra-escolar. - São Cristóvão: UFS, 2005. 
PEREIRA, Ana Paula Costa. Educação não-formal tendo como exemplo de modelo pedagógico o método escoteiro. Monografia de conclusão de curso de graduação como Bacharel em Pedagogia. Rio de Janeiro: Univercidade, 2004.

PESTALOZZI, J. H. Antologia de Pestalozzi. Trad. Lorenzo Luzuriaga. Buenos Aires: Losada, 1946.

POWELL, Baden Lord. Caminho para o sucesso. 2. ed. Rio de Janeiro: Escoteira, 1984.

POWELL, Baden Lord. Guia do chefe Escoteiro: teoria do adestramento escoteiro, um subsídio para a tarefa dos chefes. 5. ed. Porto Alegre: Ed. Escoteira, União dos Escoteiros do Brasil, 2000.

THOMÉ, Nilson. Movimento Escoteiro: Projeto Educativo Extra-Escolar. Revista HISTEDBR. Campinas, n. 23, p. 171-194, set. 2006.

VIDAL, Diana Gonçalves. Escola Nova e o processo educativo. In: LOPES, Eliane Marta Teixeira; FARIA FILHO, Luciano Mendes e VEIGA, Cyntia Greive. 500 anos de educação no Brasil. Belo Horizonte: Autentica, 2000. p. 497-518.

WEBER, Max. Ensaios de Sociologia. 5. ed. Tradução de Waltensir Dutra. Rio de Janeiro: LTC Editora, 2002.

2

Doutora em Educação pela Universidade Federal do Rio Grande do Norte (UFRN). Professora PPG 1 da Universidade Tiradentes. Membro do Grupo de Pesquisa em História das práticas educacionais - GPHPE. Email: raylane_navarro@unit.br 